\title{
Active Combustion Control of Diesel HCCI Engine: Combustion Timing
}

M. Hillion, J. Chauvin and O. Grondin

IFP, France.

N. Petit

Ecole des Mines de Paris, France

Copyright (C) 2008 Society of Automotive Engineers, Inc.

\begin{abstract}
We propose a model based control strategy to adapt the injection settings according to the air path dynamics on a Diesel HCCI engine. This approach complements existing airpath and fuelpath controllers, and aims at accurately controlling the start of combustion. For that purpose, start of injection is adjusted based on a Knock Integral Model and intake manifold conditions. Experimental results are presented, which stress the relevance of the approach.
\end{abstract}

\section{INTRODUCTION}

In the context of environmental restrictions and sustainable development, pollution standards have become more and more stringent over the last 15 years. Engine pollutant emission reduction has then become a topic of major interest for engine development. Lately, two main strategies have been explored: namely after-treatment and improved combustion modes. For Diesel engines, cost of after treatment devices are usually high. In turn, this has spurred a major interest in developments of cleaner combustion modes such as the Highly Premixed Combustion modes (HPC), including Homogeneous Charge Compression Ignition (HCCI). HCCI combustion requires the use of high Exhaust Gas Recirculation (EGR) rates. The air charge admitted in the cylinder is significantly diluted, which reduces nitrogen oxides $\left(\mathrm{NO}_{\mathrm{x}}\right)$ emissions by lowering the maximum temperature during combustion (see [1]).

In this paper, we focus on the HCCI mode which has a great potential in terms of $\mathrm{NO}_{\mathrm{x}}$ reduction and is also the most challenging from a control perspective (see [2] and [3]).

The several phases of the combustion can be described according to the timeline detailed in Figure 1. There are two main phases corresponding to the airpath subsystem (which involves the intake manifold, the intake throttle, the turbocharger, and the EGR valve) and the fuelpath subsystem (which consists of the injectors). The HCCI combustion mode is highly sensitive to the thermodynamic conditions at the intake. Accurate airpath control and adaption of the fuelpath are thus required to manage the HCCI combustion.

Airpath controllers have long been proposed (see [4], [5] and their references). They result in efficient tracking of the intake manifold variables (reference total mass, burned gases rate (BGR), and temperature of the intake charge) even during transients. Usually, three main actuators are employed (EGR valve, intake throttle and turbocharger).

Classic fuelpath controllers can be described as follows. During the cylinder compression phase, fuel is injected and mixed to the compressed air and burned gas mixture. The fuel vaporizes and auto-ignites after the so-called ignition delay (see Figures 1 and 2). Standard fuelpath control strategies focus on controlling injected fuel mass. Eventually, a smoke limiter can be added on, providing a fuel mass limiter based on a fuel/air ratio limitation to avoid smoke emissions during transients. This is usually sufficient to produce the torque requested by the driver.

As we will now discuss it, these controllers are often not sufficient to maintain a stable Diesel HCCI combustion. In fact, and by contrast to conventional Diesel combustion mode, slight offsets of cylinder initial conditions (e.g. pressure, temperature, or composition) easily cause problems. In practice, if the fuelpath controller is not coordinated to the airpath controller, combustion stability is jeopardized during transients. This is clearly visible in Figure 3e where combustion timings are reported. Large overshoots or undershoots reflect the fact that the combustion is not stabilized during transients. Actually, this can easily lead to stall. This can be seen in Figure 3 where experimentally observed misfire is reported (at time 30s). In details, one can see in Figure 3a that the produced torque drastically drops during transient resulting in stall. In the setup used to obtain these results, a classic airpath and fuelpath control strategy 
is considered. Our focus is on developing an improved method capable of achieving the desired transients. To address the discussed issues, i.e. to circumvent changes in the cylinder initial conditions, we propose to use the start of injection (soi) as an actuator to control the start of combustion during BGR (Burned Gas Rate), pressure and temperature transients. This is the main contribution of this paper. A noticeable point of our approach is that this control variable can be used on all commercial line engines without requiring any hardware upgrade. Controlling the start of combustion ( $s o c)$ is an efficient strategy in the presented context of HCCI engines. Indeed, instead of a classic flame propagation phenomenon, spatially distributed starts of combustion are simultaneously observed in the chamber.

In this paper, we assume that the soc can be modeled by a Knock Integral Model (KIM) (see [6], [7] or [1]). To guarantee that the soc occurs at a desired setpoint, we update the soi according to a first order development of the KIM. As already mentioned, controlling the soc represents a first step toward more general active combustion control methods. Other interesting possibilities could include the control of numerous scheduling variables such as the middle of combustion. They are the subject of ongoing research.

The paper is organized as follows. First, we detail existing combustion control technologies that we wish to complement and present our approach. After a presentation of the KIM we base our study on, along with the main physical assumptions underlying our work, we formulate the control problem, and propose a solution at first order. Experimental results obtained on a 2.2 liter four cylinder direct injection engine are then reported and discussed. Conclusions and future work are to see at the end of the paper.

\section{CURRENT COMBUSTION CONTROLLERS AND PRO- POSED IMPROVEMENT}

A complete nomenclature of engine variables is given in Table 1. In generally observed engine setups, airpath and fuelpath controllers are used to guarantee that engine variables (pressures, temperatures, and injected fuel mass among others) track reference values. These controllers are used in the context of actual vehicle implementation which imply frequent transients due to varying driver torque demands $(\overline{I M E P}$ : Indicative Mean Effective Pressure) and engine speed $\left(N_{e}\right)$. In turn, these demands result in frequent transients for reference airpath and fuelpath variables. Typical histories of setpoint signals $\bar{P}_{\text {intake }}, \bar{X}, \bar{\theta}_{\text {soi }}$ are reported in Figure 3 .

While both controllers seem to work simultaneously, stall is often observed during transients. This clearly appears in Figure 3a at time $31 \mathrm{~s}$. The produced torque drop to zero making the engine to stall. We now give some insight into this phenomenon. In open loop, the airpath and the fuelpath subsystems have slow $(\simeq 1 \mathrm{~Hz})$ and fast $(\simeq 50 \mathrm{~Hz})$ dynamics, respectively. In closed loop, the airpath subsystem cannot be rendered arbitrarily fast. The culprits are the turbocharger inertia and recirculation holdups. Neglecting fuelpath transients, injection parameters are instantaneously set to values corresponding to the targeted steady states $\left(\left(\bar{\theta}_{\text {soi }}, \bar{m}_{i n j}\right)=f(\overline{I M E P}, N e)\right)$. While this strategy is

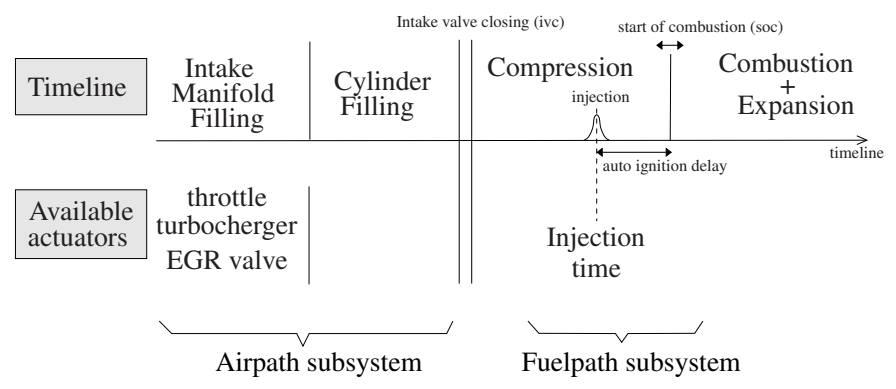

Figure 1: Timeline of Diesel engine cycle with direct injection
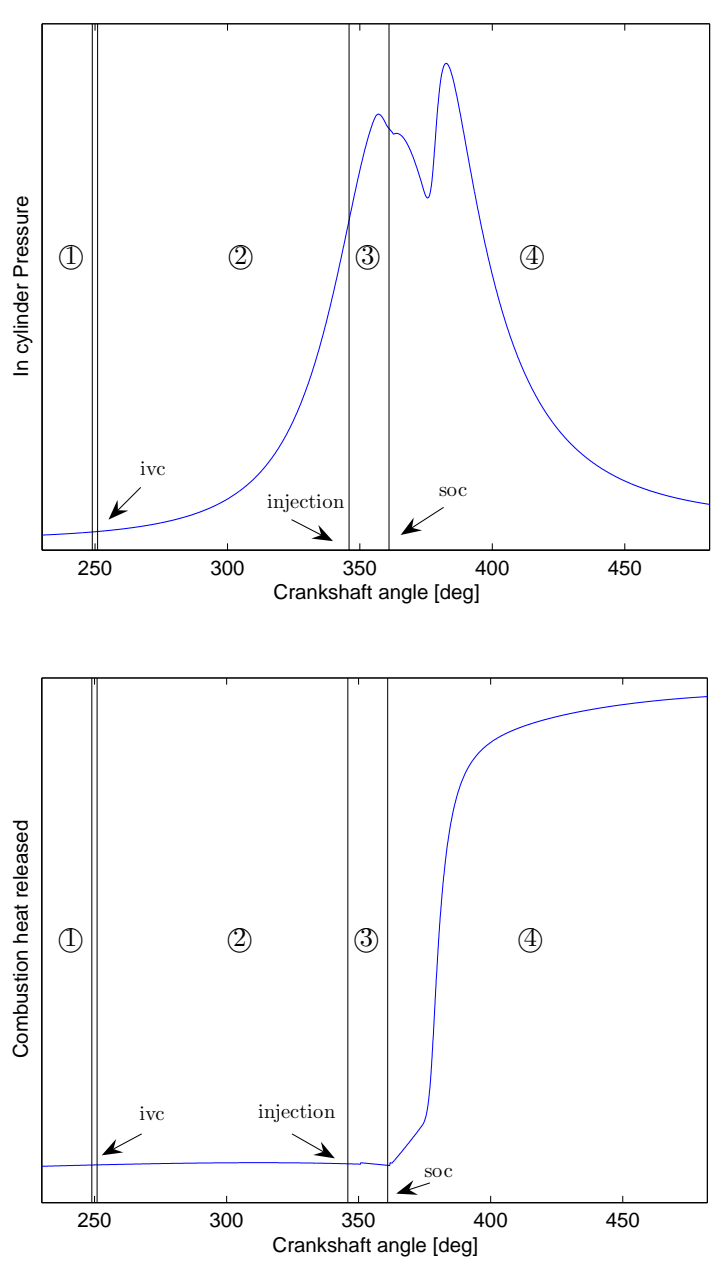

Figure 2: Experimental results: In-cylinder pressure and Combustion heat released during one cycle $\left(N_{e}=1500 \mathrm{rpm}\right.$, $I M E P=6 b a r)$ : (1) filling the cylinder, (2): compression, (3): auto ignition, (4): Combustion and expansion, ivc: intake valve closing, soc: start of combustion. (360 corresponds to the Top Dead Center)

sufficient in conventional Diesel mode, this is not the case in HCCI mode. A typical scenario is as follows. Figure 3 shows a torque transient on a 4-cylinder HCCI engine using this injection strategy. In Figures $3 \mathrm{~d}$ and $3 \mathrm{~b}$, it appears that the airpath controller regulates the intake manifold pressure and BGR around their reference values. Tracking is not instantaneous though and regulation errors appear in transients. Bias in steady state are mainly due to calibration problems and are not interfering with the presented work. On the other hand, fuel injection 


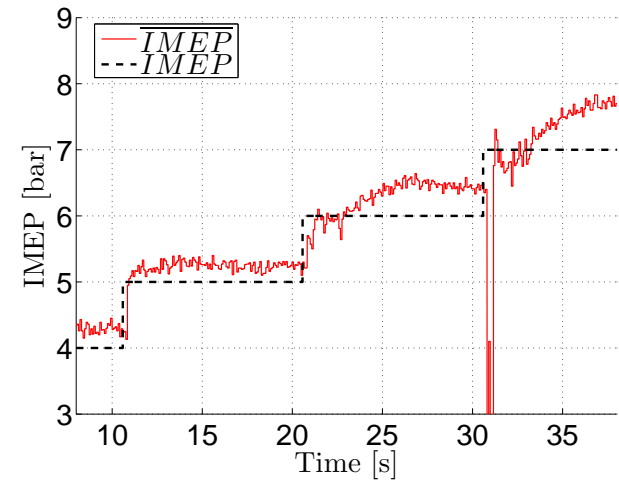

(a) Torque

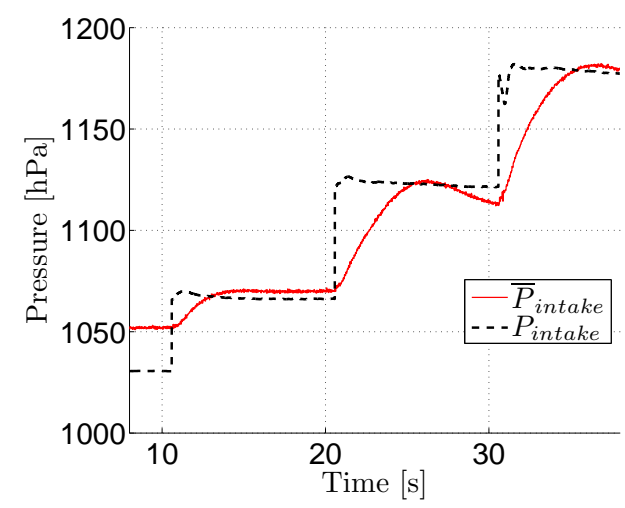

(d) Intake Manifold Pressure

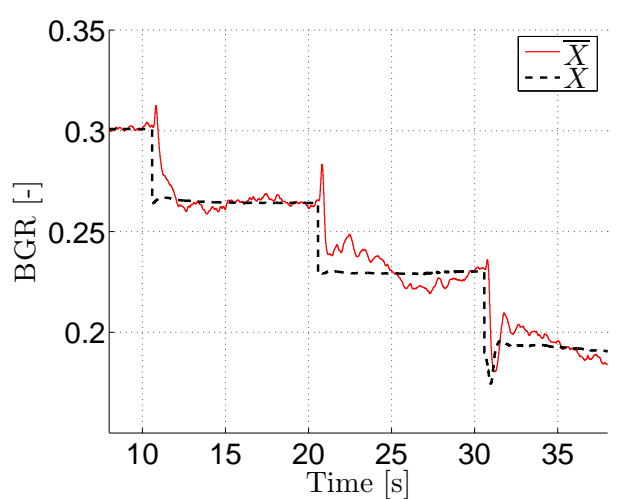

(b) Intake Manifold Burned gas rate

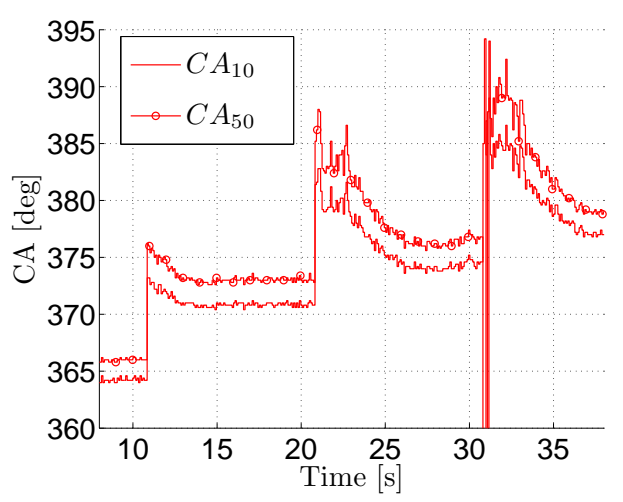

(e) CA10 \& CA50 (360 correspond to the TDC)

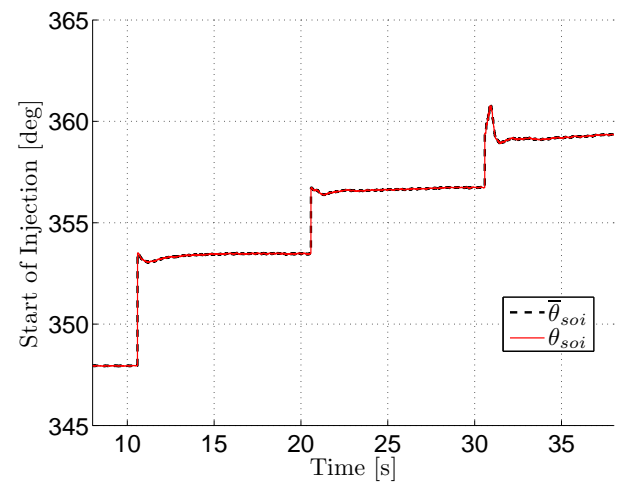

(c) soi (360 correspond to the Top Dead Center)

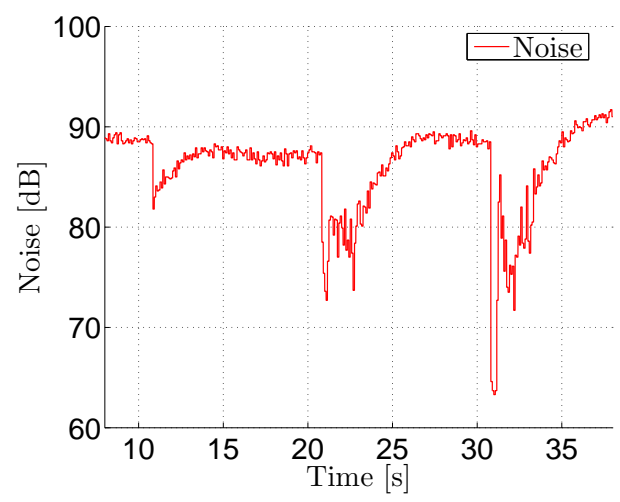

(f) engine noise

Figure 3: Experimental results on a 4-cylinder HCCI engine with direct injection. Charge transient at constant speed of 1500rpm. Comparison with and without the proposed soi correction. Parameters with overbar refer to tracked reference set points.

timing and fuel mass are instantaneously set to reference values corresponding to the targeted steady states (see 3c). Finally, Figures $3 \mathrm{a}$ and $3 \mathrm{f}$ stress that this strategy, and the corresponding mismatch between airpath and fuelpath variables, lead to large noise variations and stall during transients. We now give an insight into the main reasons of these phenomena.

\section{POSSIBLE UPGRADE}

Two main timing variables permit to sketch the quality of the combustion. These are the $s o c$ and the middle of the combustion. One often assumes that if these timing variables are efficiently controlled, the combustion will take place in a desired way. The soc (which is defined by $\mathrm{CA}_{1}$ ) is difficult to measure and is often replaced, on experimental test benches, by the $\mathrm{CA}_{10}\left(\mathrm{CA}_{\mathrm{X}}\right.$ is defined as the cranshaft angle where $\mathrm{X}$-per-cent of the fuel as been burned which are post-reconstructed from in-cylinder pressure measurements). The middle of the combustion is defined as the $\mathrm{CA}_{50}$. Figure $3 \mathrm{e}$ shows that the existing fuelpath control strategies fail to efficiently reduce tracking errors on $\mathrm{CA}_{10}$ and $\mathrm{CA}_{50}$. Combustion occurs then too early or too late, leading to instabilities, stall, and large noise variations.

Controlling the combustion timings (soc or $\mathrm{CA}_{\mathrm{X}}$ ) is then the key to HCCI engine control. In that way, a particular phenomenon has to be accounted for. The fuel injection does not directly initiate the combustion (this is rather different from spark advance in spark ignited engines). In fact, combustion occurs after the auto ignition delay (defined as the time be- tween soi and soc). Actually, both physical and chemical processes must take place before the combustion actually starts. The physical processes are the vaporisation of the fuel followed by its mixing with the air/burned-gases charge. The chemical processes are the pre-combustion reactions which do not release significant energy but lead to the auto ignition of the fuel/air/burned gases mixture. This delay depends on the physical conditions of the mixture (pressure, temperature, composition, fuel/air ratio) (see [1]). During transients, due to the airpath dynamics, the physical conditions are not at their reference value so that the ignition delay is not the reference one. On the other hand, the fuel is injected at its reference time value. Start of combustion occurs then too late or too soon.

The combustion starts after the auto ignition delay. The heat release rate depends also on the physical conditions of the mixture and on other parameters such as the available kinetic energy (see [8] or [9]). Researches have thus been carried out to control combustion timing in order to stabilize the whole combustion process. We now sketch an overview of the literature.

In [10], Haraldsson et al. present closed-loop combustion control using Variable Compression Ratio (VCR) as actuator. Changing the compression ratio directly impacts on the rise of pressure and temperature in the cylinder during compression, making differences in thermodynamic conditions during auto ignition and combustion. This is then used to control the $\mathrm{CA}_{50}$.

In [11], Olsson et al. present a dual-fuel solution. These two 
fuels have different auto-ignition properties. Taking advantage of this, $\mathrm{CA}_{50}$ can be regulated by changing the recipe of the mixture to be injected.

In [12], [13] or [14] the authors present HCCI control results based on a Variable Valve Train (VVT) actuation, which allows to trap hot exhaust gases in the cylinder from one cycle to the next. The charge temperature can thus be modified. The whole combustion process is then delayed or advanced.

\section{PROPOSED UPGRADE}

All the controllers presented in the previous Section use high frequency in-cylinder sensors and/or additional actuators (VCR, dual-fuel system, VVT). Such technical solutions are costly. Rather, to control the $s o c$, we propose a solution requiring only standard devices available on all commercial-line engines. A main advantage is that our method does not require cylinder pressure sensors.

Consider the fuelpath subsystem whose dynamic behavior, as previously discussed, is inconsistent with the dynamic behavior of the airpath subsystem. This subsystem is controlled by the fuel injection. The injected mass is used to produce a reference torque and it cannot be changed without jeopardizing performance. Therefore, only one degree of freedom of the fuelpath remains as possible additional control variable. It is the soi which appears in the combustion timeline in Figure 1.

In [15], Vigild et al. propose a soi adaptation to the intake ma-

Table 1: Nomenclature

\begin{tabular}{|lll|}
\hline Symb. & Quantity & Unit \\
\hline$\theta$ & Crankshaft angle & {$[\mathrm{deg}]$} \\
$P(\theta)$ & Cylinder volume & $\mathrm{m}^{3}$ \\
$T(\theta)$ & Cylinder pressure & $\mathrm{Pa}$ \\
$X$ & Cylinder temperature & $K$ \\
$\phi$ & Fuel/air ratio (equivalence ratio) & - \\
$V_{i v c}$ & In-cylinder volume at $i v c$ & $\mathrm{~m}^{3}$ \\
$P_{i v c}$ & In-cylinder pressure at $i v c$ & $\mathrm{~Pa}$ \\
$T_{i v c}$ & In-cylinder temperature at $i v c$ & $\mathrm{~K}$ \\
$V_{c y l}$ & Displaced volume & $\mathrm{m}^{3}$ \\
$P_{i n t}$ & Intake manifold pressure & $\mathrm{Pa}$ \\
$T_{i n t}$ & Intake manifold temperature & $\mathrm{K}$ \\
$\theta_{\text {soi }}$ & Start of injection & {$[\mathrm{deg}]$} \\
$\theta_{\text {soc }}$ & Start of combustion crankshaft angle & {$[\mathrm{deg}]$} \\
$m_{i n j}$ & Injected fuel mass & $\mathrm{mg} /$ stroke \\
$\gamma$ & Ratio of specific heats & - \\
$\eta_{v o l}$ & Volumetric efficiency & - \\
$I M E P$ & Indicative Mean Effective Pressure & $\mathrm{bar}$ \\
$N_{e}$ & Engine speed & $\mathrm{rpm}$ \\
\hline
\end{tabular}

nifold conditions based on look-up tables. This strategy resulted in a much better HCCI combustion stability but suffer from the large calibration effort needed to construct the correction maps.

In our approach, we propose to cascade the control of the $s o c$ $\left(\theta_{\text {soc }}\right)$ onto the soi $\left(\theta_{\text {soi }}\right)$ variable. This implies that, instead of constant values corresponding to references, $\theta_{\text {soi }}$ has nonconstant values during transients. Our control strategy is based on an ignition delay model, and, thus, does not need any incylinder sensors. It is in fact open loop. This model involves physical parameters of the gases aspirated in the combustion chamber (i.e. BGR, temperature, pressure, air/fuel ratio) and parameters of the fuel injection (i.e. soi, injected fuel mass).

\section{MODELLING}

\section{KNOCK INTEGRAL MODEL}

Our control strategy is based on an auto ignition delay model usually used to predict the start of combustion. Many models have been proposed in the literature, depending on the engine, the fuel and/or the working conditions. However, all these models are expressed under the Knock Integral Model originally proposed in [7]. This model gives an implicit relation between $\theta_{\text {soi }}, \theta_{\text {soc }}$ and the physical in-cylinder parameters such as $P(\theta)$, $T(\theta), X$, the fuel/air ratio $\phi$ under the following integral form

$$
\int_{\theta_{\text {soi }}}^{\theta_{\text {soc }}} \frac{\mathcal{A}(p(\theta))}{N_{e}} d \theta=1
$$

where $\mathcal{A}$ is an Arrhenius function, and $p(\theta)$ is a vector of incylinder physical properties. In [8], Barba et al. adapted a phenomenological model for conventional Diesel applications

$$
\begin{aligned}
p(\theta) & =(P(\theta), T(\theta), \phi) \\
\mathcal{A}(p(\theta)) & =c_{1} \phi^{c_{2}}\left(\frac{P(\theta)}{P_{\text {ref }}}\right)^{c_{3}} \exp \left(-\frac{T_{A}}{T(\theta)}\right)
\end{aligned}
$$

where $c_{1}, c_{2}, c_{3}, P_{\text {ref }}$, and $T_{A}$ are constant parameters. In [6], Swan et al. use the following Arrhenius function

$$
\begin{aligned}
p(\theta) & =(P(\theta), T(\theta), X, \phi) \\
\mathcal{A}(p(\theta)) & =\frac{\phi^{x}}{\left(C_{1}+C_{2} X\right) \exp \left(b P(\theta)^{n} / T(\theta)\right)}
\end{aligned}
$$

where $x, C_{1}, C_{2}, b$ and $n$ are constant parameters. In [16], Lafossas et al. extend the KIM to large burned gases rates. The proposed model is thus suitable for HCCI combustion

$$
\begin{aligned}
p(\theta) & =(P(\theta), T(\theta), X)^{T} \\
\mathcal{A}(p(\theta)) & =\frac{A}{1+C X} P(\theta)^{n} \exp \left(-\frac{T_{A}}{T(\theta)}\right)
\end{aligned}
$$

where $A, C, n$, and $T_{A}$ are constant positive parameters. The last model is used throughout the paper and experiments, but one have to keep in mind that our control strategy can be used with the Models (2), (3) or any other (smooth) function $\mathcal{A}$ using exactly the same approach.

\section{RELATING THE KNOCK INTEGRAL TO AVAILABLE} MEASUREMENTS 


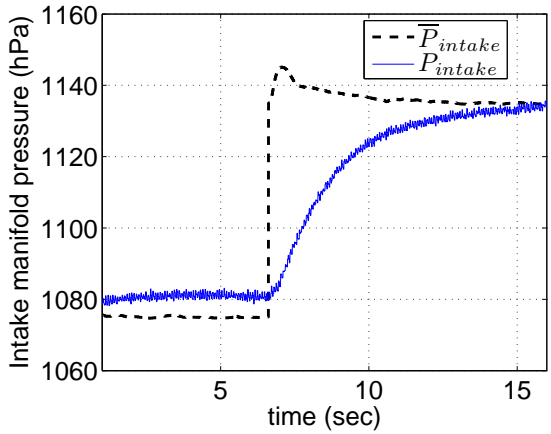

(a) Intake Manifold Pressure

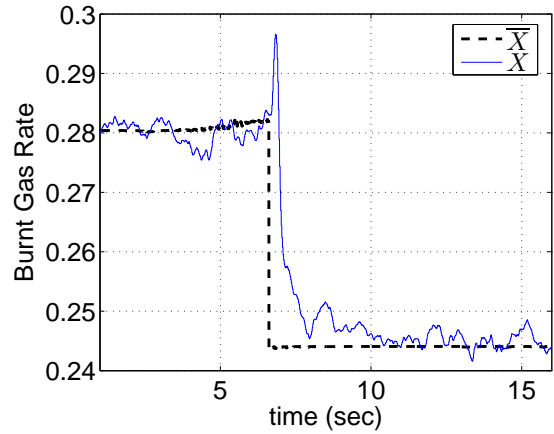

(b) Intake Manifold Burned Gas Rate

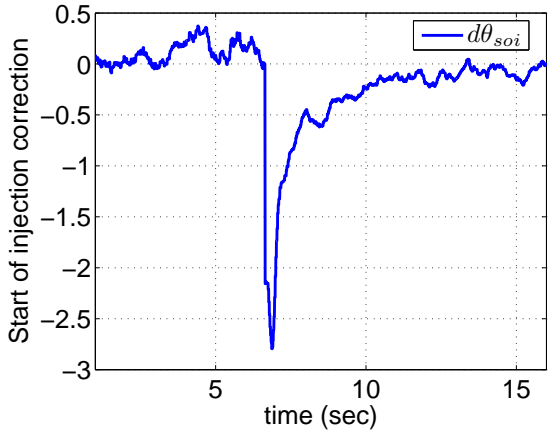

(c) soi correction

Figure 4: Experimental results on a 4-cylinder HCCI engine with direct injection. Charge transient at constant speed of 1500rpm. Effect of intake manifold pressure and burned gases rate on the soi correction.

The proposed model (1) is expressed in terms of in-cylinder thermodynamics quantities $(P(\theta), T(\theta)$, and $X)$ which are not directly measured on commercial line engines. Therefore, we rewrite it in terms of different parameters. To compute the in-cylinder pressure $(P(\theta))$ and in-cylinder temperature $(T(\theta))$ during compression, we assume that a static relation holds. In particular, the transformation is considered isentropic. Classically, during this isentropic transformation, $P V^{\gamma}$ and $T V^{\gamma-1}$ are both constant. In these relations, $V$ represents the cylinder volume, which is perfectly known as a function of the crankshaft angle $\theta$. This thermodynamic assumption (see e.g. [17]) is supported by the fact that, during the compression stroke, gas temperature is much lower than during the combustion stroke. In short, during the compression stroke, wall heating losses are neglected.

We consider the ivc (intake valve closing) as initial time for the isentropic transformation. These considerations yield to

$$
\begin{aligned}
& P(\theta)=P_{i v c} v_{i v c}(\theta)^{\gamma} \\
& T(\theta)=T_{i v c} v_{i v c}(\theta)^{\gamma-1} \\
& \text { with } \quad v_{i v c}(\theta) \triangleq \frac{V\left(\theta_{i v c}\right)}{V(\theta)}
\end{aligned}
$$

The cylinder pressure at $i v c$ is assumed equal to the intake manifold pressure right before the $i v c$ which is measured. This assumption is supported by the fact that the pressure equilibrium is reached at the $i v c$ between the intake manifold and the cylinder. The cylinder temperature at $i v c$ is reconstructed from the intake manifold temperature (measured) and the volumetric efficiency (usually mapped) via the ideal gas law (in the following equation $M_{i v c}$ is the trapped gas mass in the cylinder)

$$
\left\{\begin{array} { r l r l } 
{ P _ { i v c } } & { = } & { P _ { i n t } } \\
{ \eta _ { v o l } } & { = } & { M _ { i v c } \frac { R T _ { i n t } } { P _ { i n t } V _ { c y l } } } \\
{ M _ { i v c } } & { = } & { \frac { P _ { i v c } V _ { i v c } } { R T _ { i v c } } }
\end{array} \Rightarrow \left\{\begin{array}{lll}
P_{i v c} & = & P_{i n t} \\
T_{i v c} & = & \frac{V_{i v c}}{V_{c y l}} \frac{T_{i n t}}{\eta_{v o l}}
\end{array}\right.\right.
$$

Finally, in (1), $X$ is assumed to be constant from the ivc to the soc. This is not unrealistic, because no chemical reaction takes place between $i v c$ and $s o c$. The burned gases rate $X$ in the cylinder is thus supposed equal to the intake manifold burned gases rate obtained from an observer presented in [4].

One can notice that we do not take into account residual in cylinder gases in the estimation of $T_{i v c}$ and $X$. Errors are thus made on the estimation of the real in cylinder conditions but this appeared to be a good compromise between reality and realtime computation of engine control.

The model used throughout this paper is the model (4) which do not depend on $\phi$. In the case of a model which depends on $\phi$, the assumptions made on $X$ can be made on $\phi$ for the exact same reasons.

Substituting equations (5) and (6) into (1), the auto ignition model takes the form

$$
\begin{aligned}
& \int_{\theta_{\text {soi }}}^{\theta_{\text {soc }}} \frac{\mathcal{A}_{i v c}\left(p_{i v c}, \theta\right)}{N_{e}} d \theta=1 \\
& \text { with } \quad p_{i v c} \triangleq p\left(\theta_{i v c}\right) \\
& \mathcal{A}_{i v c}\left(p_{i v c}, \theta\right) \triangleq \mathcal{A}(p(\theta))
\end{aligned}
$$

Equation (7) summarizes the influence of the physical parameters values at $i v c$ on the start of combustion. In particular, equation (4) becomes

$$
\begin{aligned}
& p_{i v c}=\left(P_{i v c}, T_{i v c}, X\right) \\
& \mathcal{A}_{i v c}\left(p_{i v c}, \theta\right)= \\
& \frac{A}{1+C X} P_{i v c}{ }^{n} v_{i v c}(\theta)^{n \gamma} \exp \left(-\frac{T_{A}}{T_{i v c} v_{i v c}(\theta)^{\gamma-1}}\right)
\end{aligned}
$$

In the whole paper, we make the classical assumption that the engine speed $N_{e}$ is constant during the whole auto ignition process (see equation 7).

\section{CONTROL PROBLEM}

At steady state, all the $p_{i v c} \triangleq\left(P_{i v c}, T_{i v c}, X\right)$ parameters are stabilized by the airpath controller to their reference values $\left(\bar{p}_{i v c}\right)$. Further, the injection timing $\theta_{\text {soi }}$ is directly set to its reference value $\left(\bar{\theta}_{s o i}\right)$ by the fuelpath controller. A reference combustion takes place. All these reference parameters have been optimized together to reach driver's demands and pollutant restrictions.

During transient, due to the non instantaneous airpath dynamic, $\delta p \triangleq p_{i v c}-\bar{p}_{i v c} \neq 0_{\mathbb{R}^{3}}$. If fuel is injected at the reference 
time $\bar{\theta}_{\text {soi }}$, then the start of combustion differs from the reference combustion one (because $\mathcal{A}_{i v c}$ depends on $p_{i v c}$ ). We propose to compensate any such known error $\delta p$ with a corrective offset $\delta \theta_{\text {soi }}$ on the injection time reference $\bar{\theta}_{\text {soi }}$ so that the actual $\theta_{\text {soc }}$ is always equal to $\bar{\theta}_{\text {soc }}$. See [18] for a more precise formulation of the proposed control problem.

\section{SOLUTION AT FIRST ORDER}

It might be difficult to find an explicit solution to the control problem presented in the previous section when considering models with an integral form (7). A simple way to proceed is to search an approximate solution. See [18], for the detailed computation of the solution for any Arrhenius function. This general solution, applied to the model (4) gives the following soi correction

$$
\delta \theta_{s o i}=\frac{1}{\mathcal{A}_{i v c}\left(\bar{p}_{i v c}, \bar{\theta}_{s o i}\right)}\left(\alpha_{P} \delta P_{i v c}+\alpha_{T} \delta T_{i v c}+\alpha_{X} \delta X\right)
$$

with

$$
\begin{aligned}
\alpha_{P} & =\frac{n}{\bar{P}_{i v c}}>0 \\
\alpha_{T} & =\frac{T_{A}}{\bar{T}_{i v c}^{2}} \int_{\bar{\theta}_{i v c}}^{\bar{\theta}_{s o c}} \mathcal{A}_{i v c}\left(\bar{p}_{i v c}, \theta\right) v_{i v c}{ }^{1-\gamma}(\theta) d \theta>0 \\
\alpha_{X} & =-\frac{C}{1+C \bar{X}}<0
\end{aligned}
$$

In practice, this correction is easily computable in real-time, because $\mathcal{A}_{i v c}$ is a known function, $\bar{P}_{i v c}, \bar{T}_{i v c}$, and $\bar{X}$ are the airpath setpoints values, $\delta P_{i v c}, \delta T_{i v c}$, and $\delta X$ are the airpath errors (differences between measured or observed values and the setpoints), $\bar{\theta}_{\text {soi } i}$ is the reference soi, and $\bar{\theta}_{s o c}$ can be calculated online using the KIM.

The signs of the correction parameters $\alpha_{P}, \alpha_{T}$, and $\alpha_{X}$ are intuitive. If the pressure error $(\delta P)$ or temperature error $(\delta T)$ are negative, meaning that pressure or temperature at the $i v c$ are lower than the reference, the mixture would auto-ignite too late. This is counterbalanced by the negative soi correction due to the pressure and temperature term (see the sign of (10) and (11)). If the composition error $(\delta X)$ is positive, meaning that the BGR is higher than the reference, the mixture is more diluted, which increases the auto ignition delay. In such cases, the soc would thus be too late. This is counterbalanced by the negative soi correction due to the BGR term (see the sign of (12)).

The influence of the pressure and BGR errors during a torque transient on the soi correction is depicted in Figure 4. During the transient, the intake manifold pressure is lower than its reference (see Figure (a)) and the intake manifold BGR is higher than its reference (see Figure (b)). Both combined effects make the soi correction negative during the transient (see Figure (c)).

\section{EXPERIMENTAL RESULTS}

\section{EXPERIMENTAL SETUP}

The experimental setup is a four cylinders light-duty direct in-

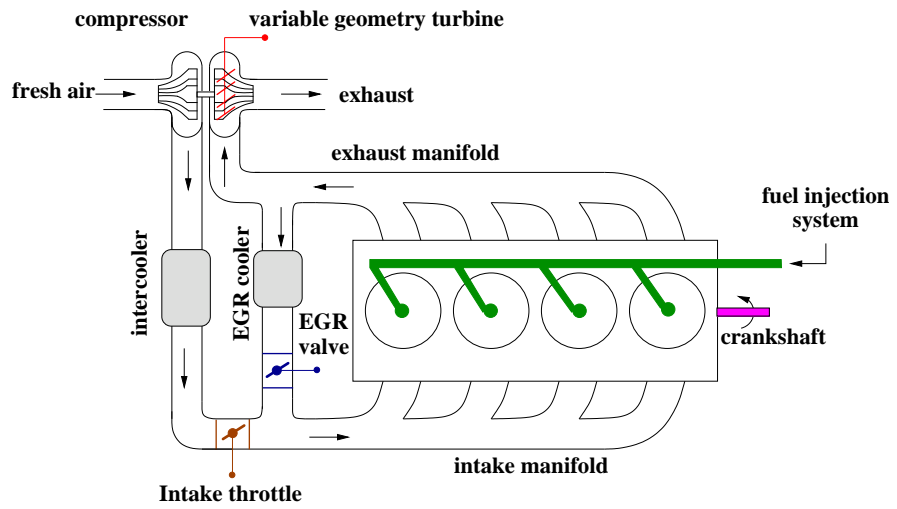

Figure 5: Scheme of a direct injection HCCI engine with high pressure EGR circuit and variable geometry Turbocharger

Table 2: Experimental setup

\begin{tabular}{|l|l|}
\hline Bore $\times$ Stroke & $87.0 \times 92.0 \mathrm{~mm}$ \\
Number of cylinders & 4 \\
Compression ratio & $14.0: 1$ \\
Displacement & 2.2 Liters \\
Injection device & Solenoid \\
Maximum injection pressure & 1600 bar \\
Piston bowl design & NADI \\
Intake Valve Closing & $\theta_{i v c}=232 \mathrm{deg}$ \\
& $(360$ is Top Dead Center $)$ \\
\hline
\end{tabular}

jection Diesel engine working in both conventional combustion mode and HCCI mode. This engine operates in HCCI mode until 7 bar of IMEP and in Diesel mode for higher load. The engine is equipped with high pressure injection system, Variable Geometry Turbocharger (VGT), Exhaust Gas Recirculation (EGR) valve and intake throttle. Exact specifications are reported in Table 2. The full path engine control is developed at IFP. Airpath control are not presented here, more details are given in $[4,5]$. The engine is connected to a brake and is fitted with pressure and temperature sensors for intake and exhaust plenums. In-cylinder pressure are recorded using an AVL piezoelectric sensor mounted on the glow plug location. The charge yielded by the piezoelectric sensor is converted into a proportional voltage signal by the charge amplifier. A specific acquisition platform has been developed at IFP in order to acquire cylinder pressure and to perform real time combustion analysis [19]. The combustion analysis results (IMEP, noise, $\mathrm{CA}_{\mathrm{X}}$ ) allow to supervise the effect of the proposed start of injection controller but are not used in the controller.

\section{CONTROLLER DESIGN}

The general control scheme is presented in Figure 6. It includes the strategy proposed in this paper to control the soc. This new strategy is included in the dark-grey module "correction calculation" which implements equations (9)-(12). In this setup, the soi $\theta_{\text {soi }}$ is not simply set to its reference value $\bar{\theta}_{\text {soi }}$ but is corrected according to the airpath errors $\delta p$. 


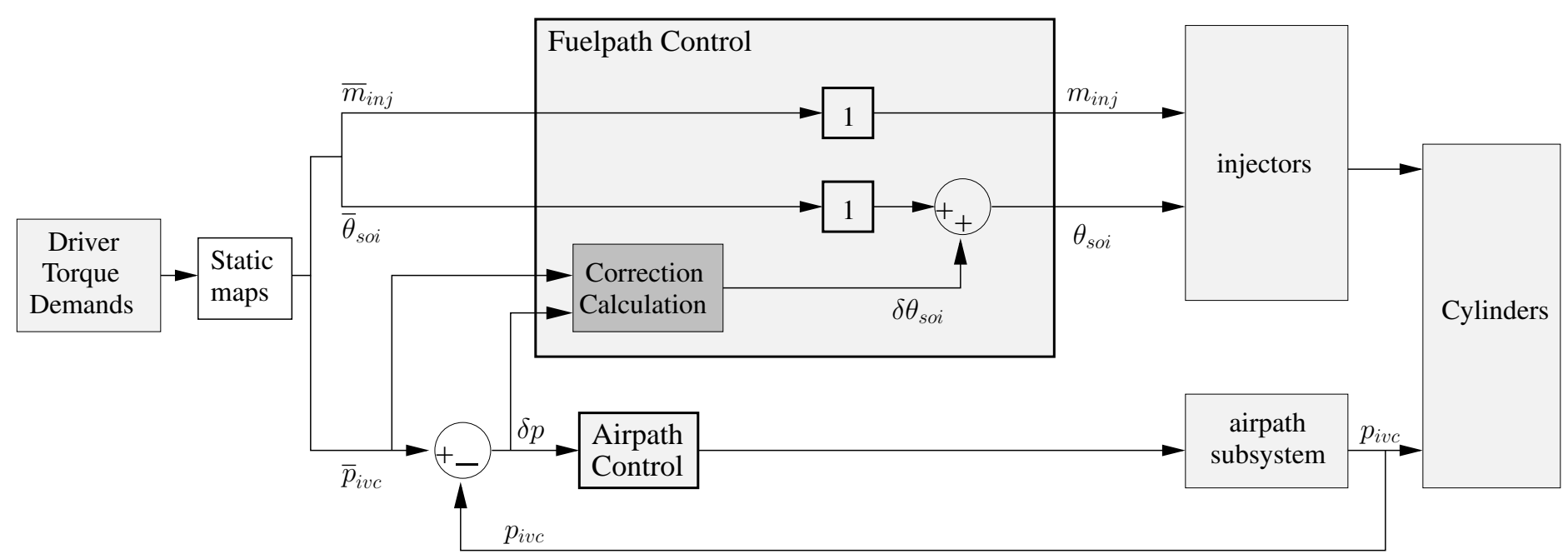

Figure 6: Design of the new control strategy. The dark grey block has been added, counterbalancing airpath errors $\delta p$ with an soi offset.

The model (4) is used in the controller design. This model has been calibrated on 50 points of the whole engine operating range using classical optimisation method.

The controller has been integrated in the IFP Diesel engine torque control structure already developed in Matlab/Simulink. RTW (Real Time Workshop) and xPC target toolboxes are used for real time code generation. The task execution time of the proposed controller is about $20 \mu \mathrm{s}$ on a $4.8 \mathrm{Ghz}$ target.

Again, one can remark that this fuelpath strategy does not need in-cylinder pressure sensors feedback.

\section{RESULTS}

Figures 7 and 8 report experimental results. Both scenarii are a varying torque demand at constant engine speed of $1500 \mathrm{rpm}$ (as the model and the presented controller are valid on the whole operating range, torque trajectories at different engine speed show the same results). For sake of comparison, experimental results for the same torque demand with (bold curve) and without (thin curve) the proposed soi controller are reported in each figure.

- The first scenario is presented in Figure 7. Figure 7a shows the torque transient trajectory. As already mentioned, the airpath controller regulates the intake manifold pressure (see 7d) and the BGR (see 7b) around their reference values. One can remark slight mismatches between both responses. This is due to slight influences of the proposed fuelpath controller on the exhaust conditions (mainly pressure and temperature) which has an impact on the intake conditions via the EGR and turbocharger physical loops (see future published work). Lastly, the soi is to see in Figure 7c.

Improvements in engine torque response are shown in Figure 7a. In fact, one can remark that stall has been avoided $(\mathrm{t}=30 \mathrm{~s})$. This is fully explainable: during this transient (6 to 7 bar IMEP step), the injection settings switch instantaneoulsy while the gas composition and pressure at the intake are still in the condition of the 6 bar of IMEP setpoint. The BGR level is too high and the intake manifold pressure is too low (the auto ignition delay is then longer than the reference). Without any start of injection compensation this leads to misfires (the mixture has not the time sufficient to auto ignite) during the time required to recover the appropriate intake manifold conditions. Secondly, torque response during transients is faster with the proposed upgrade (the reader can compare both dynamic responses of the Figure 7a at time 20s).

At last, Figure 7 e presents the evolution of the $\mathrm{CA}_{10}$. During transients, the large overshoots have disappeared. The $\mathrm{CA}_{10}$ reach much sooner it's steady state value. Combustion stability against intake manifold conditions has thus been considerably improved (misfire risks are even much lower).

- The second scenario is reported in Figure 8 with the same presentation than the previous. One can remark that the $\mathrm{CA}_{10}$ improvements (see 8e) are not as good as in the previous scenario. In fact, BGR and pressure errors during transients are larger (see Figures $8 \mathrm{~b}$ and $8 \mathrm{~d}$ ) and the linear assumption of the soi correction may reach its limits. However, torque response is better during transients (see Figure $8 \mathrm{a}$ ) and one can easily remark that the engine noise transients have been improved too. With the classical fuelpath strategy, noise level varies a lot during torque demand transitions. On the other hand, with the proposed correction strategy, noise transients happen faster and over and undershoots are much smaller or even disappear (see Figure $8 \mathrm{f}$ ). One can thus reasonably expect improvements in acoustic comfort.

In steady state, the airpath regulation may suffer from some device ageing or valve clogging (such as the EGR valve) as it is to see in Figures $8 \mathrm{~d}$ and $8 \mathrm{~b}$. It results in a non zero soi correction during steady state (see Figure $8 \mathrm{c}$ ). Combustion timing is then closer to the reference one, which has been optimized without airpath regulation errors. The proposed controller improves then the combustion stability against hardware problems too or airpath static errors. 
In the presented results, intake manifold temperature variations are not taken into account in the soi computation. In fact, the engine intercooler and EGR cooler have been sized to make the intake manifold temperature changes as small as possible. Moreover, it's quite difficult to have an intake manifold temperature measurement rapid enough to use it in the soi controller (classical temperature sensors are slow). This will be corrected in a future work.

The proposed control strategy is mainly active during transients. Thus, it does not modify engine performances such as pollutant emissions at steady state. During transients, the presented results have shown that combustion stability has been largely improved. Emissions that are due to these instabilities have then been drastically reduced. For example, high $\mathrm{HC}$ emissions during engine stall have disappeared.

\section{CONCLUSION AND FUTURE WORK}

An improvement for the fuelpath control strategy of HCCI Diesel engine has been presented. Instead of directly setting the soi to its reference value, we propose to adapt the fuel injection settings according to the intake manifold conditions. This controller is mainly based on the linearization of an auto ignition delay model (KIM) and an estimation of in-cylinder conditions at the $i v c$ (which in our case is inferred from intake manifold signals). The advantages of the proposed method are

- the soi correction is computed from a physical model and does not need any calibration. Only the four model parameters are optimized over the whole engine operating range

- The soi correction is computed using standard engine measurements and does not require in-cylinder pressure sensors.

The presented experimental results stress the relevance of this new approach. Stall problems during transients are solved and combustion stability (one great challenge in HCCI combustion mode) is improved. At the light of these results, controlling the soc seems to be an appropriate solution to improve the stability of the HCCI combustion. The soc control cancels noise peaks during transients when BGR level is to low compare to its setpoint. The soi correction compensates the BGR settling time (airpath time constant).

This method is very general and can be applied to other combustion systems and engine architectures.

- Engines with low pressure EGR circuits suffering from even larger delays.

- CAI (Controlled Auto Ignition) engines are gasoline engines using an homogeneous charge ignited by compression. The same KIM are used to model the auto ignition delay. The proposed soi correction strategy can then be used with a suitable model parameters. In that case, the temperature correction should have a greater influence due to internal gas recirculation.
- Engines operating with fuel with variable properties (flex fuel). Each fuel has a different auto ignition behavior classically modeled by a cetan/octan number which can easily been include in a KIM as a new physical property. If measurement or estimation of these properties are available, they can be included in the soi correction.

\section{AKNOWLEDGEMENT}

The authors would like to gratefully thank Gilles Corde for his scientific support.

\section{REFERENCES}

[1] J. Heywood. Internal combustion engine fundamental. Mc Graw-Hill, Inc, 1988.

[2] J. Kahrstedt, K. Behnk, A. Sommer, and T. Wormbs. Combustion processes to meet future emission standards. In Motortechnische Zeitschrift, pages 1417-1423, 2003.

[3] B. Walter and B. Gatellier. Near zero NOx emissions and high fuel efficiency diesel engine: the $\mathrm{NADI}^{T M}$ concept using dual mode combustion. In Oil and Gas Science and Technology, volume 58, pages 101-114, 2003.

[4] J. Chauvin, G. Corde, and N. Petit. Transient control of a Diesel engine airpath. In American Control Conference, 2007.

[5] J. Chauvin, G. Corde, and N. Petit. Constrained motion planning for the airpath of a Diesel HCCI engine. In Conference on Decision and Control, 2006.

[6] K. Swan, M. Shahbakhti, and C.R. Koch. Predicting start of combustion using a modified knock integral method for an HCCI engine. In Proc. SAE World Congress, number 2006-01-1086, 2006.

[7] J.C. Livengood and P.C. Wu. Correlation of auto ignition phenomena in internal combustion engines and rapid compression machine. In Fifth International Symposium on Combustion, pages 347-356, 1955.

[8] C. Barba, C. Burkhardt, K. Boulouchos, and M. Bargende. A phenomenological combustion model for heat release rate prediction in high-speed di diesel engines with common rail injection. In Proc. SAE World Congress, number 2000-01-2933, 2000.

[9] F.G. Chmela and G. C. Orthaber. Rate of heat release prediction for direct injection diesel engines based on purely mixing controlled conditions. In Proc. SAE World Congress, number 1999-01-0186, 1999.

[10] G. Haraldsson, P. Tunestål, B. Johnansson, and J. Hyvonen. HCCI combustion phasing with closed-loop combustion control using variable compression ratio in a multi cylinder engine. In Proc. SAE World Congress, number 2003-01-1830, 2003. 
[11] J-O. Olsson, P. Tunestal, and B. Johansson. Closed-loop control of an HCCI engine. In Proc. SAE World Congress, number 2001-01-1031, 2001.

[12] C.J. Chiang, A. G. Stefanopoulou, and M. Jankovic. Nonlinear observer-based control of load transitions in homogeneous charge compression ignition engines. In IEEE Transaction on Control System Technology, volume 15, may 2007.

[13] K. Chang, G.A. Lavoie, and A. Babajimopoulos. Control of a multi-cylinder HCCI engine during transient operation by modulating residual gas fraction to compensate for wall temperature effects. In Proc. SAE World Congress, number 2007-01-0204, 2007.

[14] H-E. Angström, B. Eriksson, and J. Wikander. Transient control of HCCI through combined intake and exhaust valve actuation. In Proc. SAE World Congress, number 2003-01-3172, 2003.

[15] C. Vigild, C.-F. Tumelaire, D. Röttger, E. Karvounis, and P.O. Calendini. Toward generic model based engine control - the concept. In E-COSM - Rencontres Scientifiques de l'IFP, pages 95-102, 2006.

[16] F.-A. Lafossas, M. Marbaix, and P. Menegazzi. Development and application of a OD D.I. Diesel combustion model for emissions prediction. In Proc. SAE World Congress, number 2007-01-1841, 2007.

[17] D. J. Rausen, A. G. Stefanopoulou, J-M. Kang, J. A. Eng, and T-W. Kuo. A mean-value model for control of homogeneous charge compression ignition (HCCI) engines. In IEEE Proceedings of American Control Conference, 2004.

[18] M. Hillion, J. Chauvin, and N. Petit. Controlling the start of combustion on an HCCI diesel engine. In American Control Conference, 2008 (submitted).

[19] O. Grondin, L. Duval, F. Guillemin, S. Ker, G. Corde, and C. Vigild. Rapid-prototyping multi-sensors processing platform for real time engine control and diagnosis. In Fifth IFAC Symposium on Advance in Automotive Control, 2007.

\section{LIST OF ABBREVIATIONS}

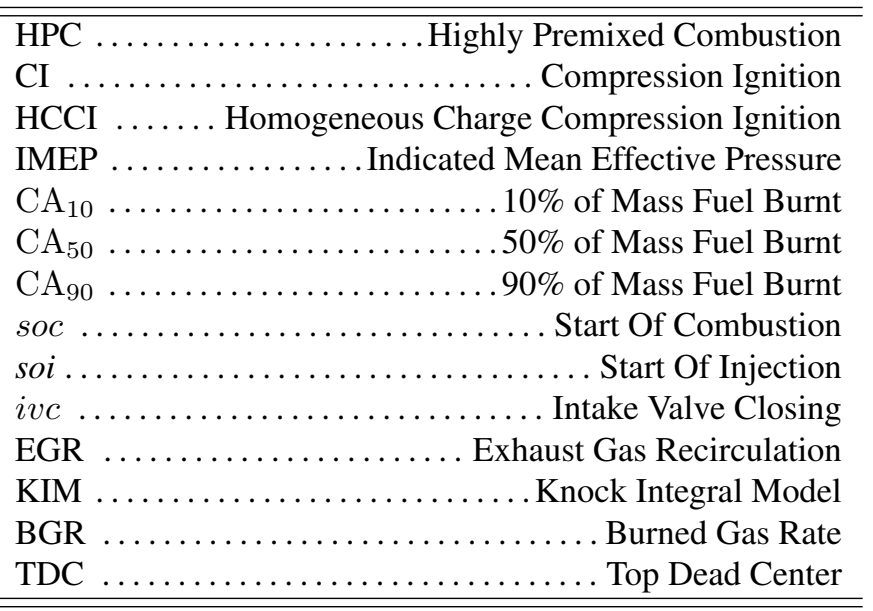




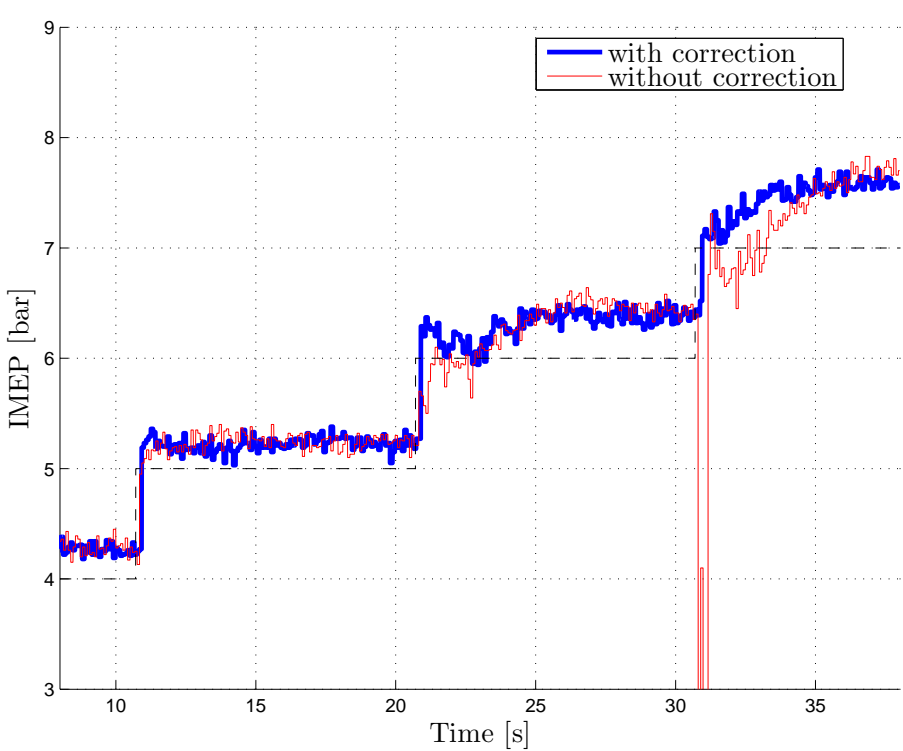

(a) Torque

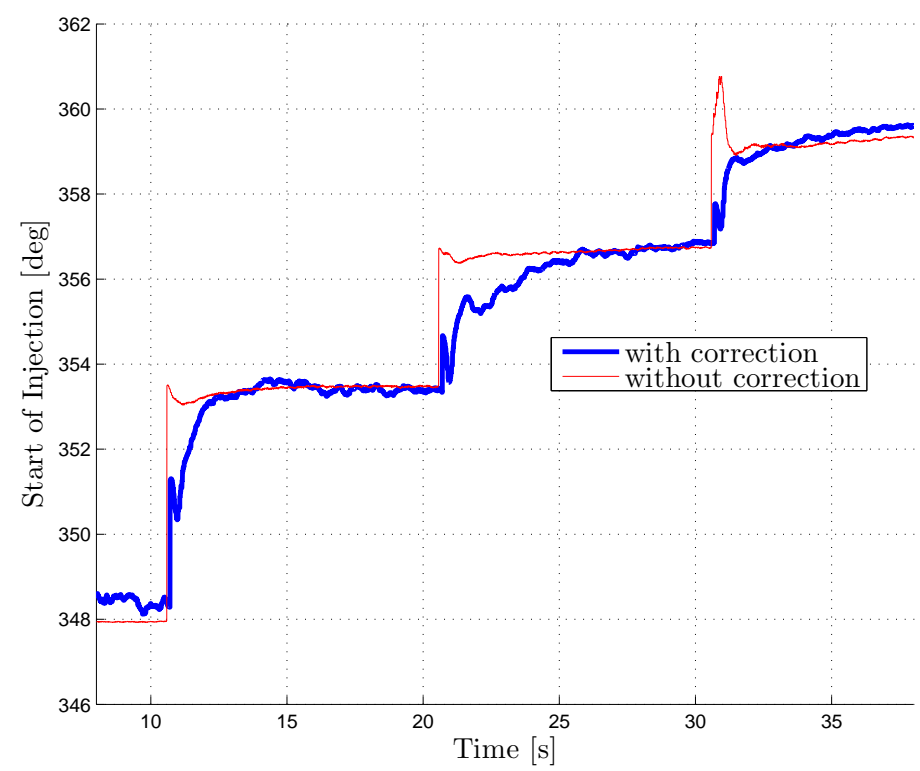

(c) soi (360 correspond to the Top Dead Center)

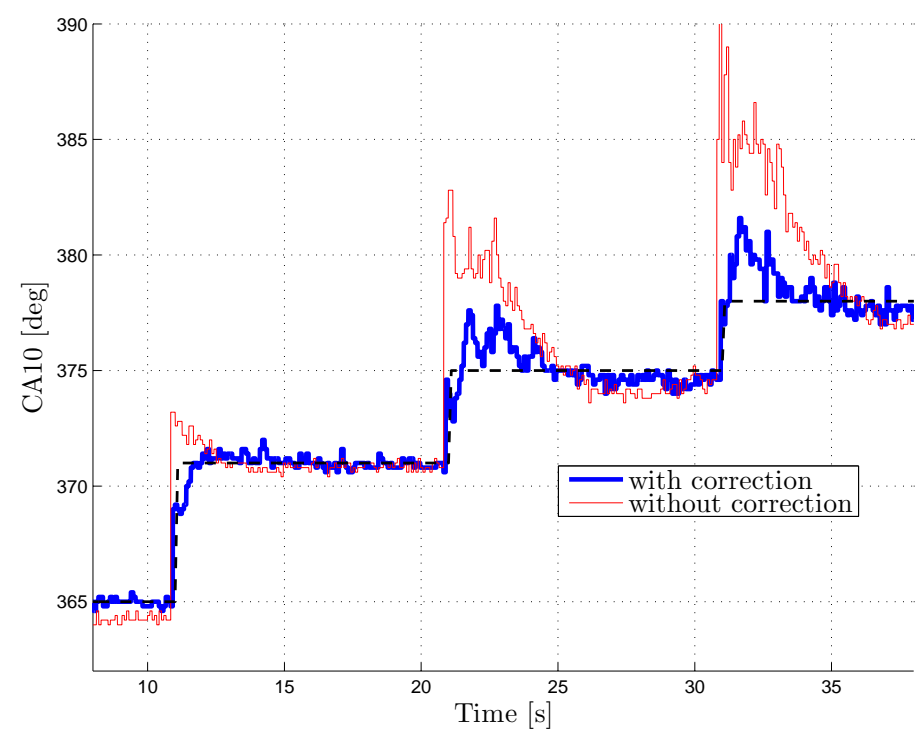

(e) CA10 (360 correspond to the TDC)

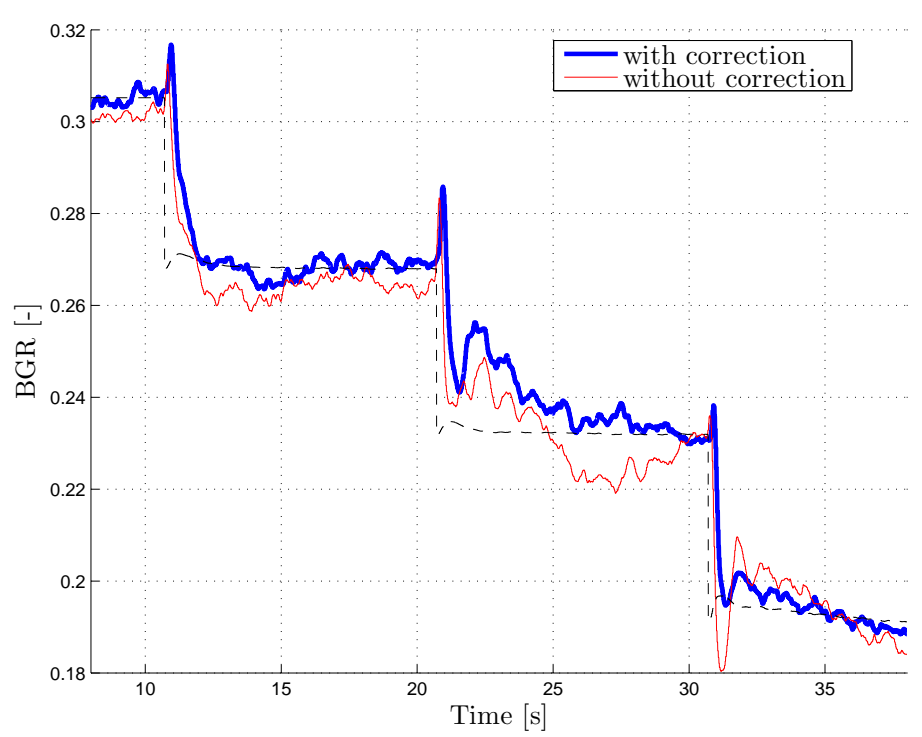

(b) Intake Manifold Burned gas rate

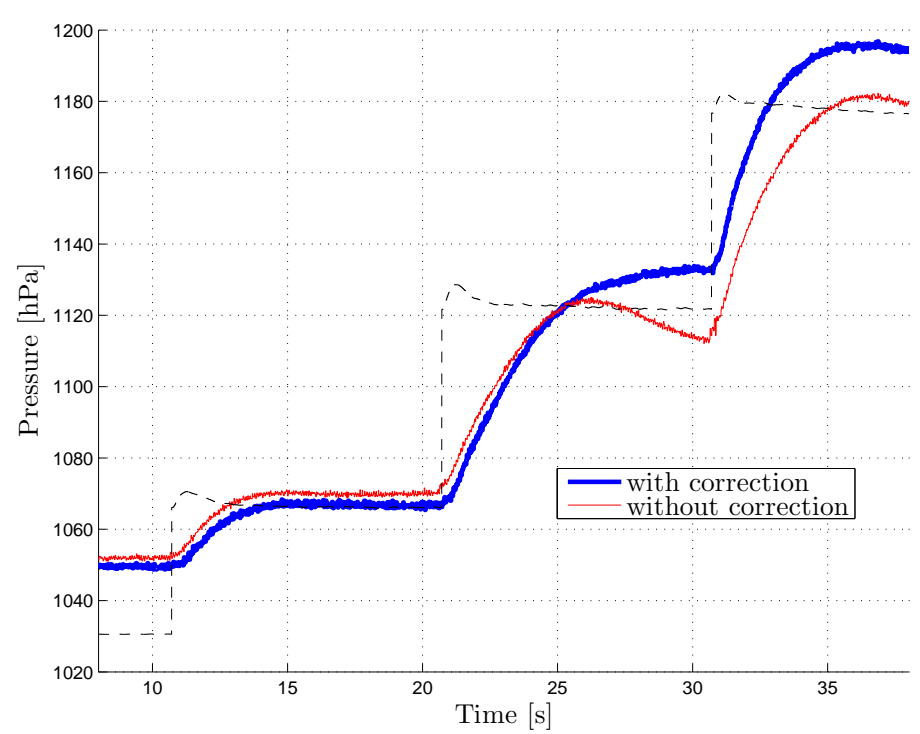

(d) Intake Manifold Pressure

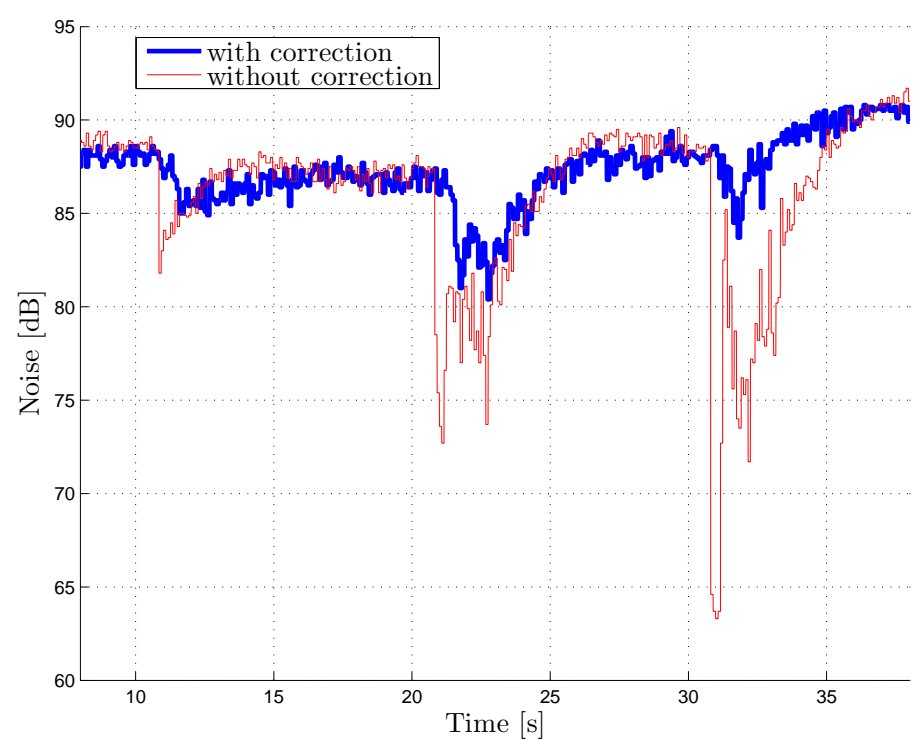

(f) engine noise

Figure 7: Experimental results on a 4-cylinder HCCI engine with direct injection. Charge transient at constant speed of 1500rpm. Comparison with and without the proposed soi correction. When plotted, dashed lines are the tracked reference set points. 


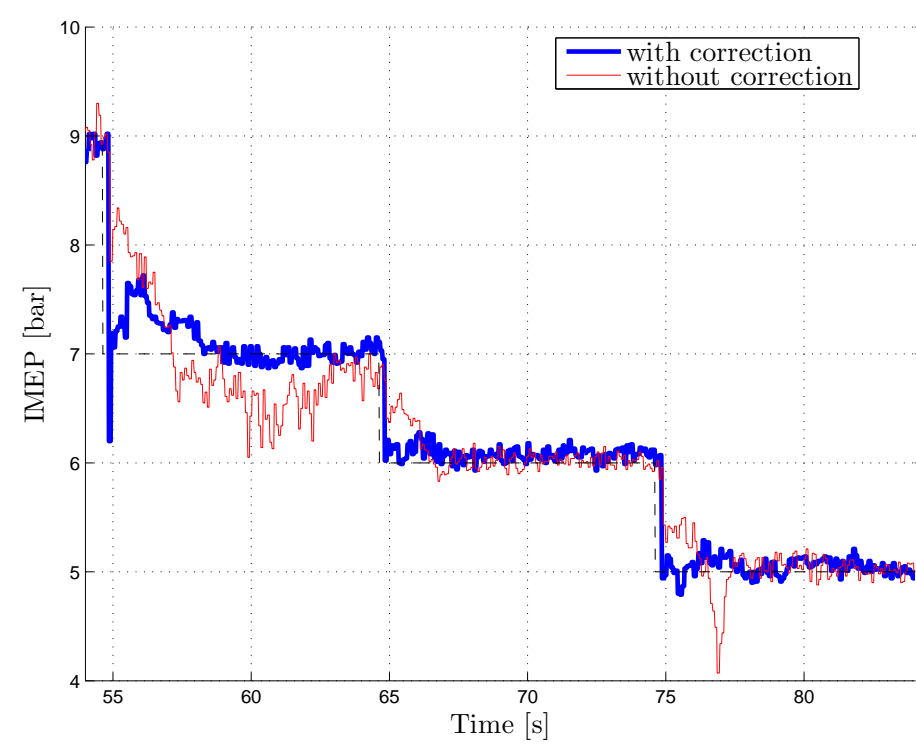

(a) Torque

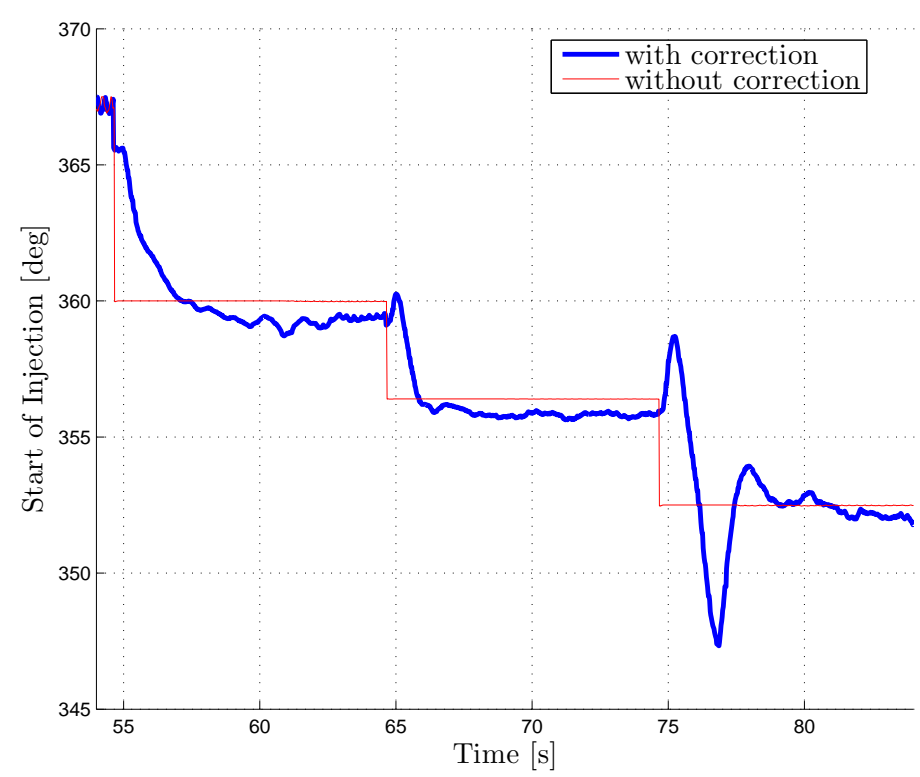

(c) soi (360 correspond to the Top Dead Center)

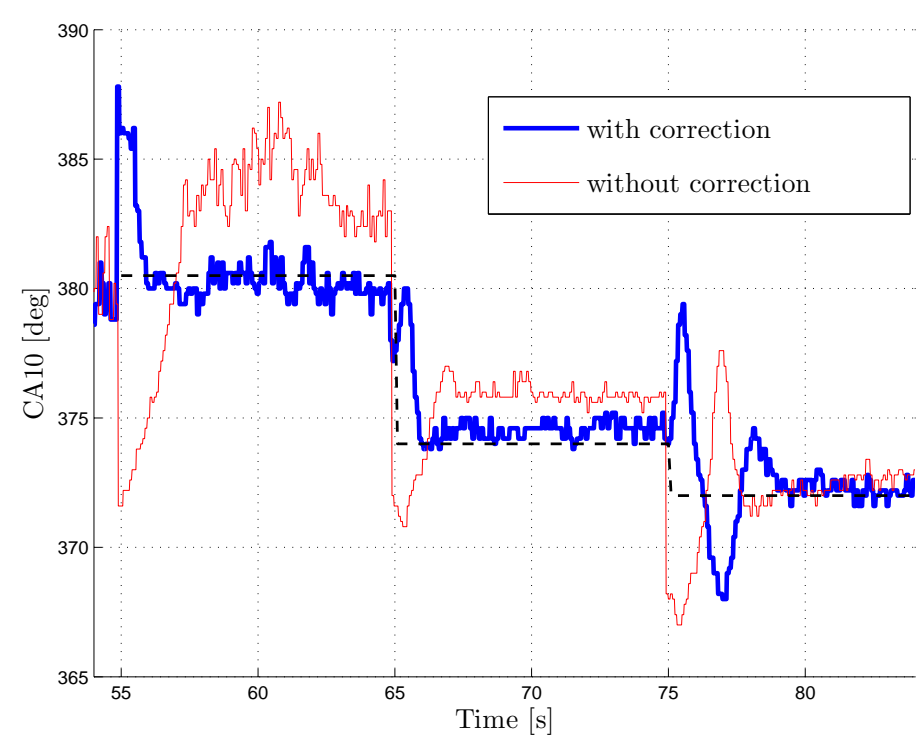

(e) CA10 (360 correspond to the TDC)

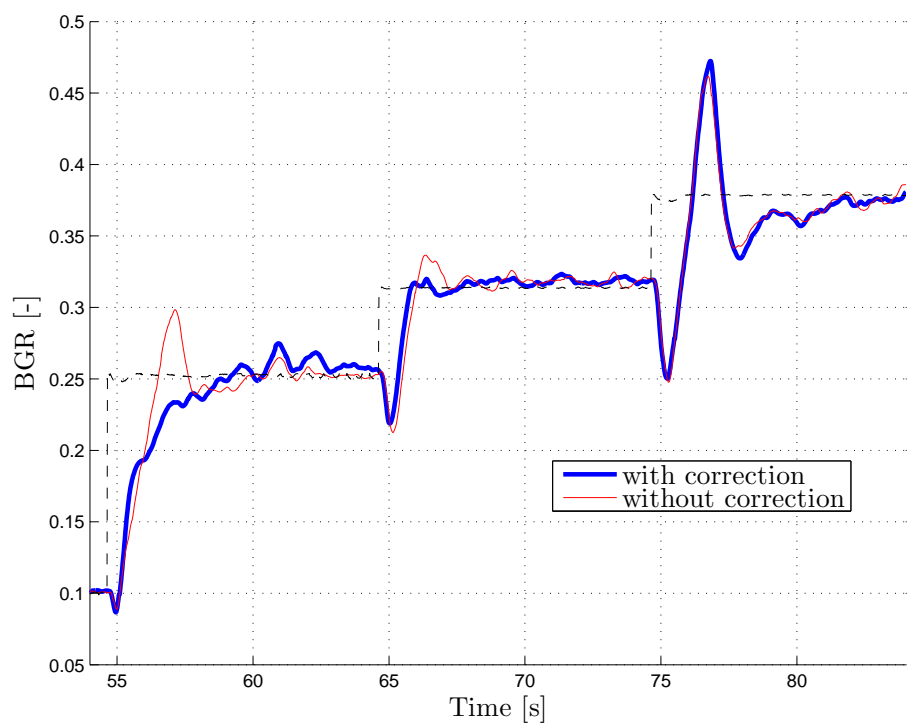

(b) Intake Manifold Burned gas rate

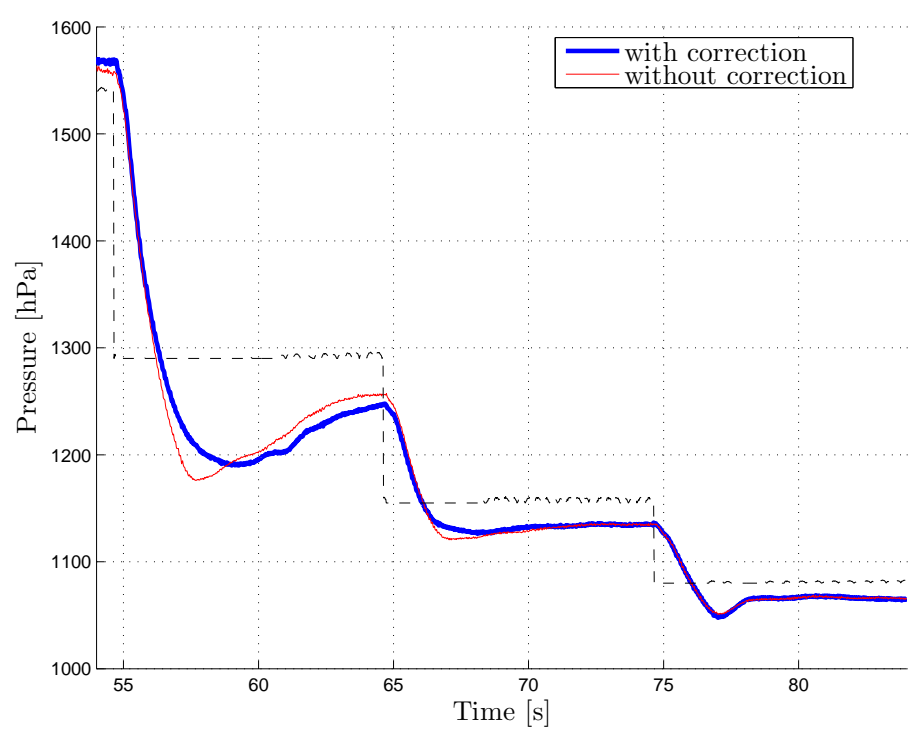

(d) Intake Manifold Pressure

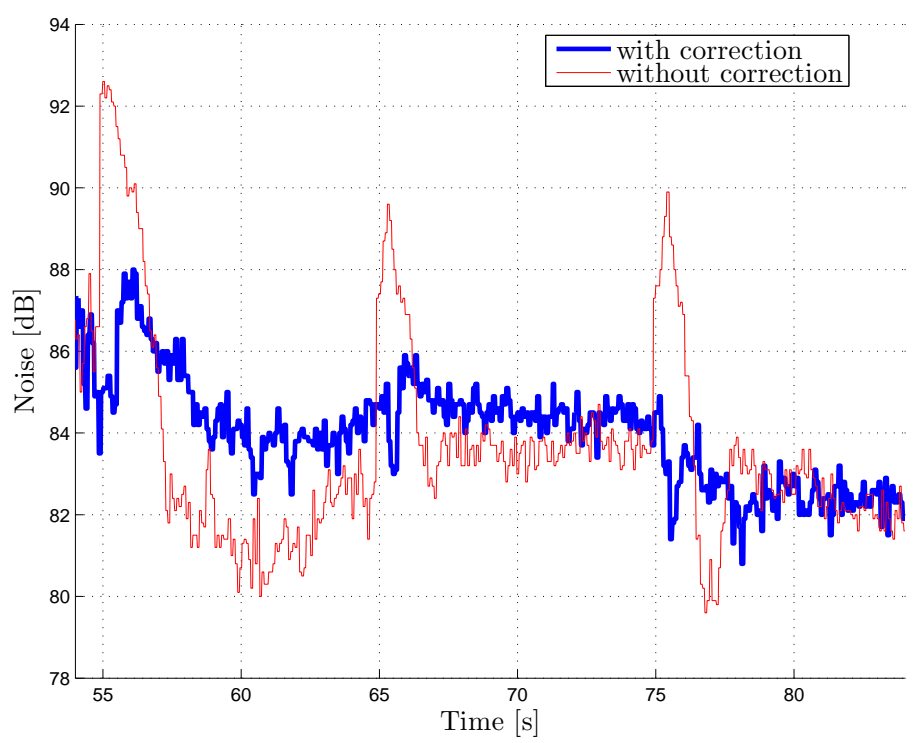

(f) engine noise

Figure 8: Experimental results on a 4-cylinder HCCI engine with direct injection. Charge transient at constant speed of 1500rpm.Comparison with and without the proposed soi correction. When plotted, dashed lines are the tracked reference set points. 